\title{
Sol-gel derived mesoporous and microporous alumina membranes
}

\author{
Berna Topuz $\cdot$ Muhsin Çiftçioğlu
}

Received: 2 April 2010/Accepted: 3 August 2010/Published online: 17 August 2010

(C) Springer Science+Business Media, LLC 2010

\begin{abstract}
Stable polymeric and colloidal boehmite sols were prepared by sol-gel process through controlled hydrolysis/condensation reactions. The particle sizes of the colloidal sols were in the $12-25 \mathrm{~nm}$ range depending on the process parameters and about $2 \mathrm{~nm}$ for polymeric sols. The presence of a significant increase in the microporosity content of the heat treated polymeric membranes relative to the mesoporous colloidal membranes might make the design of thermally stable microporous alumina membranes with controlled pore structures possible. The phase structure evolution in the $600-800{ }^{\circ} \mathrm{C}$ range had shown that the crystallization of the gamma alumina in the amorphous matrix starts at about $800{ }^{\circ} \mathrm{C}$. This indicated that the pore structure stability may be enhanced through processing up to this relatively high temperature in polymeric alumina derived unsupported membranes. The permeance values of the two and three layered colloidal alumina membranes were observed to be independent of pressure which implies that the dominant gas transport mechanism is Knudsen diffusion in these structures. This was also supported by the $2.8 \mathrm{~nm} \mathrm{BJH}$ pore sizes of the colloidal membranes. The Knudsen diffusion equation derived permeances of the polymeric alumina membranes with thicknesses of about $300 \mathrm{~nm}$ were determined to be very close to the experimentally determined permeance values.
\end{abstract}

Keywords Sol-gel - Alumina membranes . Thermal stability · Gas permeation

B. Topuz $(\bowtie) \cdot$ M. Çiftçioğlu

Chemical Engineering Department, İzmir Institute

of Technology, 35430 Urla, Izmir, Turkey

e-mail: bernatopuz@gmail.com

\section{Introduction}

Hydrolysis and condensation reactions in sol-gel processing play a critical role in determining the pore structure of the membranes and the bulk materials. The extent of hydrolysis/condensation reactions determines essentially the structure of sol particles which can be either colloidal particles or polymeric species. Partial hydrolysis with a less than stoichiometric amount of water is the primary necessity for the formation of less developed nanoscale polymeric sol structures. Sol-gel process is one of the most appropriate methods for the preparation of porous inorganic membranes with a wide range of controlled pore structures for different applications [1]. A microporous structure can only be obtained by the interpenetration of low branched polymeric species [2, 3].

The ability to control the reaction conditions like acid type/amount, water amount, chelating agent amount/type and reaction temperature can make the preparation of tailor made alumina layers with desired pore structures possible. The basic method for the preparation of stable boehmite sols/gels with plate shaped crystals defined originally by [4] can be summarized as the hydrolysis of the alkoxide in excess water to precipitate a hydroxide, the subsequent peptization of the hydroxide with the addition of acid, and the formation of a gel by partial removal of the solvent. Reaction temperatures of $80{ }^{\circ} \mathrm{C}$ and above promote the boehmite formation but at lower temperatures bayerite [beta $\mathrm{Al}(\mathrm{OH})_{3}$ ] is formed leading to unstable sols [4-6].

Ceramic membranes designed to have controlled asymmetric structures and surface properties can make them very attractive for many membrane-based separations because of higher thermal-mechanical-chemical stability and gas flux compared to their polymeric counterparts. The macroporous ceramic supports are expected to mechanically hold the thin 
separative layer and also be chemically inert. The generally used composite asymmetric ceramic membrane structure consists of several layers with a gradual decrease in pore size and thickness on a macroporous support to minimize the resistance to gas transport through the membrane [1]. Although dry pressing and extrusion are conventional techniques for the preparation of ceramic membrane supports, macroporous supports with excellent surface homogeneity and properties have been prepared through colloidal processing (slip casting/filtration) of stable dispersions without strong agglomerates [7, 8]. Microporous silica membranes with large surface areas on defect free gamma alumina intermediate layers and tubular alumina supports were prepared by ceramic extrusion method towards the preparation of substrate bundles for $\mathrm{H}_{2}$ separation recently by Yoshino et al. [9]. Rapid hybrid processing method comprised of sol-gel and CVD was used for the preparation of silica membranes on capillary substrates with gamma alumina intermediate layers (with $5 \mathrm{~nm}$ pore sizes) in order to improve the separation and permeation properties [10].

The presence of smooth surfaces, fine and uniform pore sizes, submicron thickness, and structural continuity in the intermediate layer is a prerequisite for defect-free thin microporous selective top layer preparation [6]. The hydro/thermal pore structure stability also has a great importance for large scale implementation of the membranes. Phase transformation temperatures primarily determine the stability of membranes since thermally activated microcrack formation on membrane surface may occur due to significant structural changes above this temperature. Decrease in surface area and increase in pore size are also consecutive results of phase transformation and sintering [11].

The number of comprehensive studies describing the design/characterization/stabilization of mesoporous $\gamma$ $\mathrm{Al}_{2} \mathrm{O}_{3}$ membrane pore structures as well as their gas transport properties has increased significantly with the synthesis of stable boehmite sols over the past three decades [6-21]. The pore structure characteristics, molecular properties of gaseous species and their interactions with the pore walls are some of the important factors for gaseous transport through porous membranes. Previous research on gas transport mechanisms through mesoporous alumina membranes has shown that Knudsen diffusion was the dominant mechanism for non-adsorbing gases $[15,16,22$, 23]. It was also reported that $\mathrm{CO}_{2}$ transport was enhanced by surface diffusion due to the strong interaction with the $\gamma-\mathrm{Al}_{2} \mathrm{O}_{3}$ surface. The $\mathrm{H}_{2}$ selectivity has been improved by the modification of internal pore walls with Pd [24] and Ni [17] in order to increase the contribution of surface diffusion at higher temperatures.

Ultra-thin silica layers $(20-30 \mathrm{~nm})$ were deposited by CVD on alumina graded structures derived from size controlled boehmite sols in the studies of Gu and Oyama $[3,25]$. The size of the boehmite crystallites were in the $30-950 \mathrm{~nm}$ range and was controlled by changing the peptization conditions by using acetic, nitric and hydrochloric acid with $\mathrm{H}^{+}$/alkoxide molar ratio in the $0.03-0.25$ range. Acetic acid was found to be more effective in obtaining stable sols in the desired size range. Alumina membranes with graded structures about $1 \mu \mathrm{m}$ in thickness with superior hydrogen permeation properties were prepared by using dilute boehmite sols. They also claimed that this graded structure resulted in higher hydrothermal stability due to a greater interaction among the particles in the region where particle size changes. The hydrothermal stability of CVD derived composite silica-alumina membranes had been improved through the formation of $\mathrm{Si}-\mathrm{O}-\mathrm{Al}$ linkages that are more resistant to the hydrolysis reaction and hence decreases the rate of densification [26].

The size, shape and degree of agglomeration of boehmite crystallites in addition to the deposition conditions during film formation determine the membrane microstructure upon heat treatment. Kuzniatsova et al. [12] compared the microstructural integrity of alumina membranes derived from unpurified and purified boehmite sols. Different techniques have been employed for the purification of sols including high speed centrifugation and ultrasound-assisted screening. Membranes prepared from purified sols appear to be much less prone to interfacial micro-cracking and have a more homogeneous structure. Application of the purified membrane precursor sols results in membranes with no detectable connected pore defects (pinholes) for a membrane thickness of larger than $500 \mathrm{~nm}$.

Although the use of colloidal boehmite sols for the preparation of mesoporous alumina membranes was extensively investigated, research on the preparation and the structure of polymeric sols as well as the preparation of polymeric alumina membranes is not widely conducted yet. This study is concerned with the synthesis and structural/gas permeation properties of sol-gel derived membranes with thin microporous alumina surface layers prepared by using polymeric sols on intermediate colloidal mesoporous alumina layers and macroporous slip-cast alumina supports. In the current study, membrane microstructure was designed through the packing of colloidal/ polymeric boehmite species and subsequent heat treatment. Stable polymeric alumina sols were prepared by the close control of sol-gel parameters including acid and water to alkoxide molar ratios and chelating agent type/ amount. Gas permeation and pore structure properties were also determined and compared with those of the alumina membranes prepared by the colloidal sol-gel route. 


\section{Materials and methods}

\subsection{Sol preparation}

Colloidal boehmite sols were prepared by the hydrolysis of aluminium isopropoxide (98\%, Aldrich) at a temperature of $90{ }^{\circ} \mathrm{C}$ for $3 \mathrm{~h}$. The hydroxide precipitate was peptized with appropriate amounts of nitric acid to form a stable colloidal suspension at about $90{ }^{\circ} \mathrm{C}$ under vigorous stirring. The $\mathrm{H}_{2} \mathrm{O} / \mathrm{Al}^{3+}$ molar ratio was 100 . Particle size was controlled by varying the $\mathrm{HNO}_{3} / \mathrm{Al}^{3+}$ mole ratio in the 0.07-0.4 range in $50 \mathrm{~mL}$ total sol volume with $0.5 \mathrm{M} \mathrm{Al}^{3+}$ equivalent [27].

Polymeric boehmite sols with water contents lower than theoretically required for complete hydrolysis and condensation reactions were prepared. Predetermined amounts of acetyl-acetone (AA-99.5\%, Fluka) and ethyl-acetoacetate (EAA-99\%, Fluka) as chelating agents were used to stabilize the products of the hydrolysis/condensation of Aluminum-trisecbutoxide (ASB-97\%, Merck) in order to prepare stable polymeric alumina sols. Parent alcohol was used with high dilution ratios $\left(0.5 \mathrm{M} \mathrm{Al}^{3+}\right.$ equivalent) as a solvent. The hydrolysis/condensation of EAA modified precursor was conducted at $90{ }^{\circ} \mathrm{C}$ for $3 \mathrm{~h}$ after the dropwise addition of predetermined amount of $\mathrm{H}_{2} \mathrm{O}$ and $\mathrm{HNO}_{3}$ to the ASB/2-Butanol/EAA mixture with constant vigorous stirring. The effects of the utilized catalyst amount, chelating agent type/concentration, and the hydrolysis ratio (mole ratio of $\mathrm{H}_{2} \mathrm{O}$ to $\mathrm{Al}^{3+}$ ) on sol stability were investigated. The codes of the polymeric boehmite sols and their respective ratios are given in Table 1 .

\subsection{Support preparation}

The $\alpha-\mathrm{Al}_{2} \mathrm{O}_{3}$ and $\mathrm{ZrO}_{2}$ support discs $(40 \mathrm{~mm}$ in diameter and $2 \mathrm{~mm}$ in thickness) were consolidated by slip casting polyelectrolyte (polyacrylic acid, PAA) stabilized 15 vol.\% alumina (AKP-50, Sumitomo Powder) and zirconia

Table 1 Synthesis parameters employed for polymeric boehmite sols

\begin{tabular}{lllll}
\hline Codes & $\mathrm{AA} / \mathrm{Al}^{3+}$ & $\mathrm{EAA} / \mathrm{Al}^{3+}$ & $\mathrm{H}^{+} / \mathrm{Al}^{3+}$ & $\mathrm{H}_{2} \mathrm{O} / \mathrm{Al}^{3+}$ \\
\hline p02 & 0.4 & & 0.35 & 1 \\
p03 & 0.3 & & 0.35 & 1 \\
p04 & 0.2 & & 0.35 & 1 \\
p1 & & 0.2 & 1.5 & 2 \\
p2 & & 0.15 & 1.5 & 2 \\
p3 & & 0.1 & 1 & 2 \\
p4 & & 0.1 & 0.5 & 2 \\
p5 & & 0.15 & 0.3 & 2 \\
p6 & & 0.3 & 0.3 & 1 \\
p7 & & 0.3 & 0.5 & 1 \\
p8 & & 0.3 & 0.5 & 1.5 \\
\hline
\end{tabular}

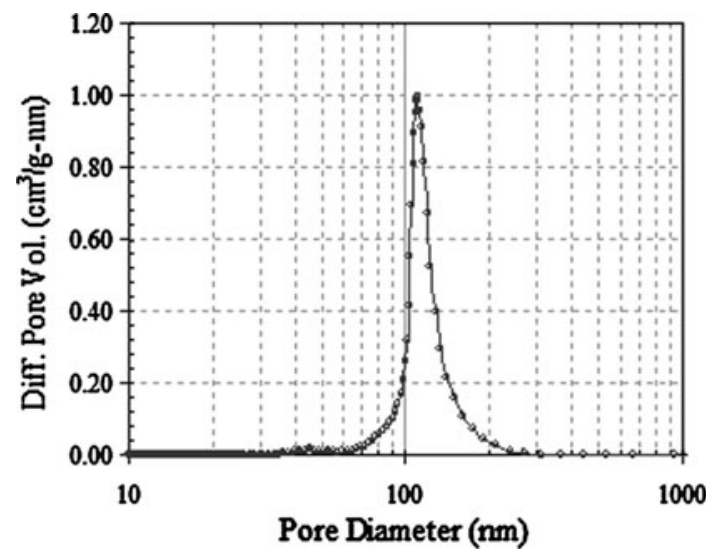

Fig. 1 Pore size distribution of slip-cast $1,150{ }^{\circ} \mathrm{C}$ treated alumina support

(TZ3Y-Tosoh) suspensions. Cast alumina and zirconia supports were heat treated at 1,150 and $1,100{ }^{\circ} \mathrm{C}$ for $3 \mathrm{~h}$ respectively with a heating rate of $10{ }^{\circ} \mathrm{C} / \mathrm{min}$. The top surfaces of the supports with about a surface roughness of $0.08 \mu \mathrm{m}$ were coated. The $\mathrm{Hg}$ intrusion pore size distribution of the heat treated alumina support is as shown in Fig. 1 (Quantachrome Corporation, Poremaster 60). The support structure had a total porosity of 0.36 with about $110 \mathrm{~nm}$ pores.

\subsection{Membrane formation}

Mesoporous alumina intermediate layers were formed by dip coating colloidal boehmite sols onto $\alpha$-alumina and zirconia supports. Dipping time and withdrawal speed were varied from 5-20 s and 50-200 $\mathrm{mm} / \mathrm{min}$ in order to control the membrane thickness on zirconia supports. Graded and ungraded membranes were prepared solely on alumina supports with $100 \mathrm{~mm} / \mathrm{min}$ withdrawal rate for $10 \mathrm{~s}$. The pore structures for both alumina and zirconia supports are previously determined to be quite similar because of the very similar powder particle sizes and densification behaviours. Three-layered membranes with ungraded structures were obtained by dipping-drying-heat treatment three times using diluted boehmite sols $\left(0.2 \mathrm{M} \mathrm{Al}^{3+}\right.$ equivalent). Membranes with graded structures were also prepared by repeating the dipping-drying-heat treatment steps three times using diluted colloidal boehmite sols with gradual decrease $(22-13 \mathrm{~nm}$ as will be given later in the results section) in particle sizes $\left(0.2 \mathrm{M} \mathrm{Al}^{3+}\right.$ equivalent). Membranes were dried for $3 \mathrm{~h}$ at $40{ }^{\circ} \mathrm{C}$ at a relative humidity (RH) of $60 \%$ (Binder-KBF 115, Constant Climate Chamber), and subsequently heat treated at $500{ }^{\circ} \mathrm{C}$ for $2 \mathrm{~h}$ with heating and cooling rates of $1.5^{\circ} \mathrm{C} / \mathrm{min}$ [28].

These mesoporous alumina layer coated supports were dip coated by polymeric boehmite sols $\left(0.15 \mathrm{M} \mathrm{Al}^{3+}\right.$ 
equivalent) with $100 \mathrm{~mm} / \mathrm{min}$ withdrawal rate for $5 \mathrm{~s}$. Drying was conducted at $40{ }^{\circ} \mathrm{C}$ at $60 \% \mathrm{RH}$ (Binder-KBF 115 , Constant Climate Chamber) overnight and the membranes were further heat treated at $500{ }^{\circ} \mathrm{C}$ for $2 \mathrm{~h}$ with heating and cooling rates of $1.5^{\circ} \mathrm{C} / \mathrm{min}$. The coating, drying and heat treatment steps were repeated twice in order to repair any defects on the first membrane layer.

\subsection{Sol and membrane characterization}

Dynamic light scattering (DLS) was used to determine the diluted sol particle size distributions at $25^{\circ} \mathrm{C}$ (ZetaSizer $3000 \mathrm{HS}$, Malvern). A He-Ne laser with a fixed wavelength of $633 \mathrm{~nm}$ was used as a light source and instrument detects the scattered light at $90^{\circ} .{ }^{27} \mathrm{Al}$ MAS NMR was employed with a 7-mm MAS (Magic angle spinning) probe to determine the coordination of the species in the polymeric boehmite sols (Bruker Superconducting FT.NMR Spectrometer, Avance $300 \mathrm{MHz}$ WB). The spinning rate of $5,000 \mathrm{~Hz}$ was applied. The surface area, pore volume and the pore size distribution of unsupported membranes prepared under identical conditions with their supported counterparts were obtained from $\mathrm{N}_{2}$ sorption isotherms (Micromeritics, ASAP 2010). The use of Type I (microporous) and Type IV (mesoporous) isotherms (both adsorption and desorption) for the analysis of pore structures towards inorganic membranes characterization is given by Burggraaf and Cot [29]. About $0.15 \mathrm{~g}$ samples were degassed for $1 \mathrm{~h}$ at $90{ }^{\circ} \mathrm{C}$ and $4 \mathrm{~h}$ at $250{ }^{\circ} \mathrm{C}$ prior to $\mathrm{N}_{2}$ adsorption. The micropore sizes were determined with the Horvath-Kawazoe (H-K) while Barreth-JoynerHallende (BJH) method was utilized for the calculation of the mesopore pore sizes. The volume of adsorbed nitrogen was used to calculate the porosity $(\varepsilon)$ according to;

$\varepsilon(\%)=\frac{V_{\mathrm{p}}}{V_{\mathrm{p}}+(1 / \rho)} \times 100$

where $V_{\mathrm{p}}$ is the pore volume $(\mathrm{mL} / \mathrm{g})$, and $\rho$ is the theoretical density of the solid phase $(\mathrm{g} / \mathrm{mL})$. FTIR spectroscopy (FTIR-8400S, Schimadzu Co.) was carried out to determine the molecular functional groups while X-ray diffraction (Philips X'pert Pro) with $\mathrm{CuK}_{\alpha}$ was employed for phase structure characterization within the $2 \theta$ range of $5-80^{\circ}$. Microstructural characterization of supported membranes was performed by scanning electron microscopy (Philips XL30 SFEG). The thermal behaviour of unsupported membranes was determined by TGA (TGA$51 / 51 \mathrm{H}$, Schimadzu) and DTA (DTA-50, Schimadzu) analyses where the samples were heated at a rate of $10{ }^{\circ} \mathrm{C} /$ min up to $1,000{ }^{\circ} \mathrm{C}$ in $\mathrm{N}_{2}$ atmosphere. The densification behaviour of alumina sol generated powders were investigated by determining the dilatometric shrinkage curves (Linseis, L76/150B) with a heating rate of $5{ }^{\circ} \mathrm{C} / \mathrm{min}$ up to $1,300{ }^{\circ} \mathrm{C}$. The $40{ }^{\circ} \mathrm{C}$ overnight dried unsupported membranes were consolidated by uniaxial pressing under a pressure of $180 \mathrm{MPa}$ for dilatometric runs.

\subsection{Gas permeation determination}

Permeation behaviour of pure gases including $\mathrm{N}_{2}, \mathrm{O}_{2}$ and $\mathrm{CO}_{2}$ was determined by using a pressure controlled deadend mode membrane test system. The pressure of the expansion chamber on the membrane feed side $\mathrm{p}_{\mathrm{h}}$ was varied in the 2-3.5 atm range and kept constant during the permeation experiments. The chamber pressure on the permeate side of the membrane was at atmospheric pressure at the beginning and increased to a final value at the end of the permeation experiment. Feed and permeate pressure transducer readings were recorded as a function of time for the determination of pure gas permeances. The permeance data were obtained in the $25-120{ }^{\circ} \mathrm{C}$ temperature range with a constant transmembrane pressure of $1 \mathrm{~atm}[28]$.

\section{Results and discussions}

\subsection{Colloidal boehmite sols}

Both colloidal and polymeric sol-gel routes were employed for the preparation of stable boehmite sols. The change in number based colloidal sol particle size with $\mathrm{H}^{+} / \mathrm{Al}^{3+}$ molar ratio is given in Fig. 2. The particle size in the colloidal sols (DLS-number based particle size of $\sim 13 \mathrm{~nm}$ ) was almost constant in the $0.07-0.25 \mathrm{H}^{+} / \mathrm{Al}^{3+}$ ratio range. The sol with $\mathrm{H}^{+} / \mathrm{Al}^{3+}$ ratio of 0.25 was used for the formation of the ungraded membranes in the rest of this work accordingly. Boehmite sols with $\mathrm{H}^{+} / \mathrm{Al}^{3+}$ molar ratio in the $0.25-0.4$ range were utilized for forming the graded intermediate layers on the supports. The sol particle

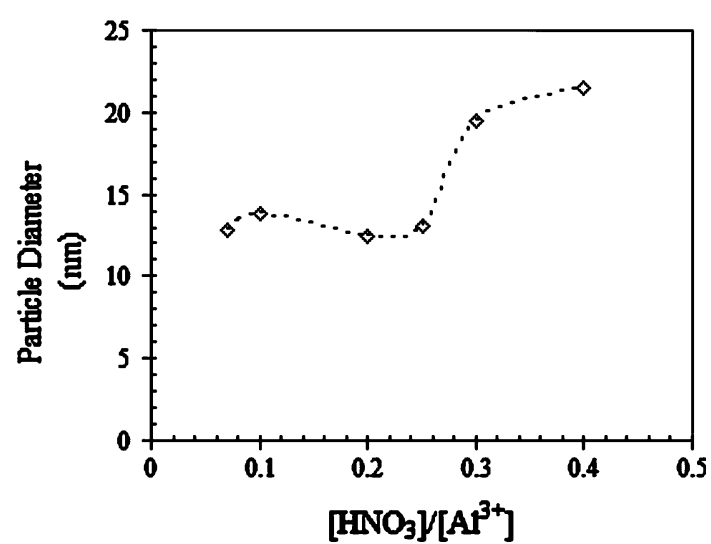

Fig. 2 Effect of acid content on particle sizes of colloidal boehmite sols 

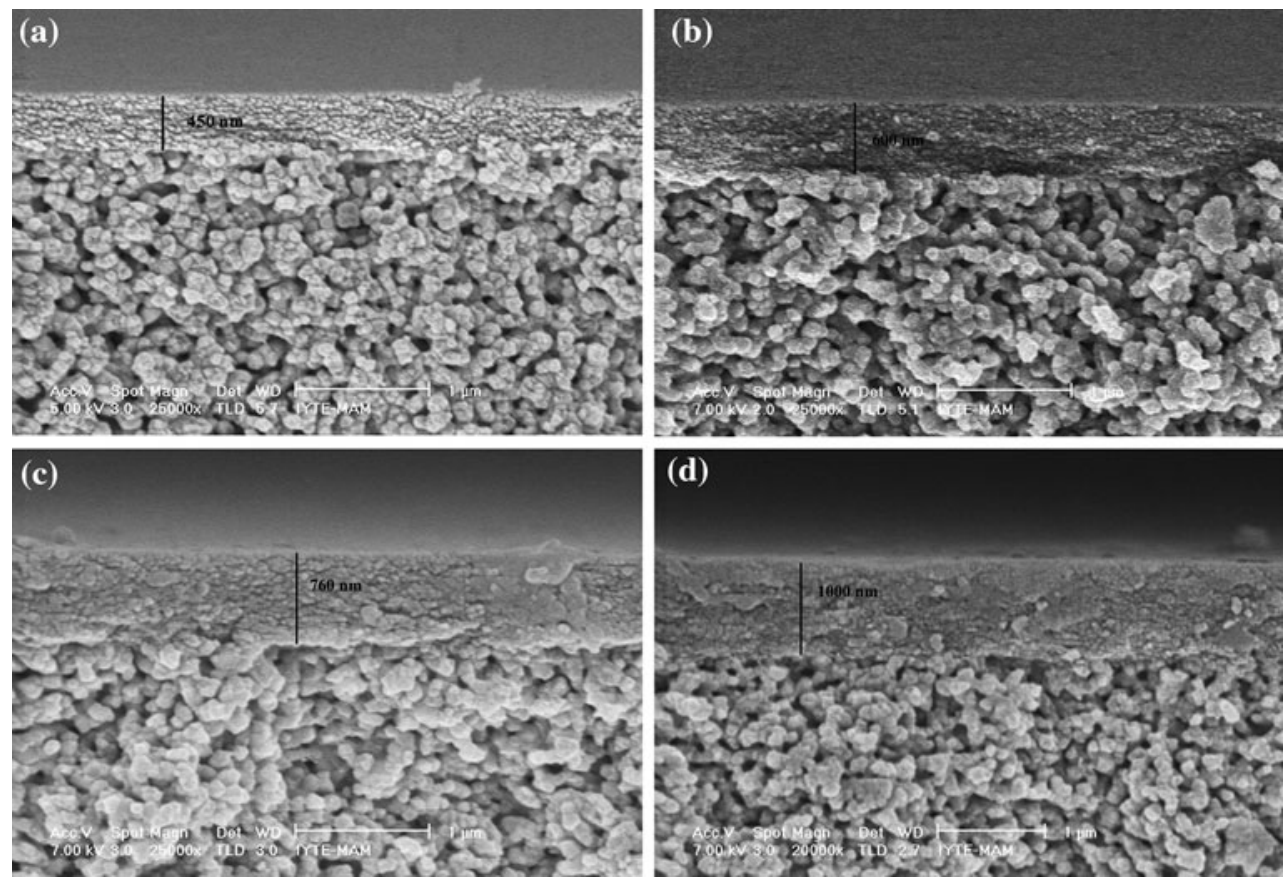

Fig. 3 SEM micrographs of cross-sections of $500{ }^{\circ} \mathrm{C}$ heat treated colloidal $\gamma-\mathrm{Al}_{2} \mathrm{O}_{3}$ layer on zirconia supports; dipping time: $10 \mathrm{~s}$ a withdrawal speed: $50 \mathrm{~mm} / \mathrm{min}$; b withdrawal speed: $150 \mathrm{~mm} / \mathrm{min}$, c withdrawal speed: $200 \mathrm{~mm} / \mathrm{min}$, d dipping time: $20 \mathrm{~s}$, withdrawal speed: $200 \mathrm{~mm} / \mathrm{min}$

size of the layers were in the order of $\sim 22>18>13 \mathrm{~nm}$ for the first, second, and the third layers, respectively.

The uniformity of the membrane layer can be achieved by controlling the dipping conditions including time and withdrawal speed as well as the solid content and $\mathrm{pH}$ of the sol. Colloidal boehmite sol $\mathrm{pH}$ was about 3.7 for the $\mathrm{H}^{+}$/ $\mathrm{Al}^{3+}$ molar ratio of 0.25 (This ratio was used for colloidal intermediate layer formation in the rest of the work unless otherwise stated) which was conveniently higher than 3.4 for the stated lower level of sol infiltration into the support [29]. The thickness of one layer mesoporous alumina membrane was varied by changing dipping time and withdrawal speed as shown in Fig. 3.

Maximum layer thickness of $1 \mu \mathrm{m}$ was obtained when withdrawal speed and dipping time were $200 \mathrm{~mm} / \mathrm{min}$ and $20 \mathrm{~s}$, respectively while the decrease in speed to $50 \mathrm{~mm} /$ min and time to $10 \mathrm{~s}$ yielded a layer thickness of $450 \mathrm{~nm}$. Highly uniform, homogeneous colloidal $\gamma-\mathrm{Al}_{2} \mathrm{O}_{3}$ layers were acquired on zirconia support. Layer deposition by dip coating process includes dipping of dry substrates into the sol and subsequent withdrawal to form a dense layer with well defined thickness [30]. Dipping time has a strong influence on the film thickness as well as the porosity and pore size of the substrate, because the capillary suction caused by the porous substrate drives the particles/polymers to concentrate on the surface if the particles do not penetrate the support pores. The thickness of the adhered layer also increases with the withdrawal speed and sol viscosity. The SEM micrographs shown in Fig. 3 are a clear indication of the ability to control the film thickness with both the dipping time and the withdrawal speed as a consequence of both slip casting and film coating mechanisms. Meanwhile, the layer thickness should be as small as possible to increase the flux without any defects on the membrane surface. The intermediate mesoporous layers were formed by coating with colloidal boehmite sols twice which was expected to yield $\gamma$-alumina films of $450 \mathrm{~nm}$ to about $1 \mu \mathrm{m}$.

\subsection{Polymeric sols}

Stable precipitate free polymeric clear boehmite sols were prepared through controlled hydrolysis/condensation reactions. Clear stable sols or precipitates were obtained with the variation of hydrolysis temperature. Temperatures lower than $80{ }^{\circ} \mathrm{C}$ resulted in precipitates while hydrolysis conducted at about $90{ }^{\circ} \mathrm{C}$ led to the formation of yellowish stable sols. The controlled hydrolysis of ASB in 2-butanol led to the formation of clear gels or stable sols depending on the $\mathrm{H}^{+} / \mathrm{Al}^{3+}, \mathrm{H}_{2} \mathrm{O} / \mathrm{Al}^{3+}$ molar ratios as well as the addition level of chelating agents. A schematic pseudophase diagram of EAA derived polymeric boehmite sols/ gels prepared in this work is given in Fig. 4 which also indicates the influence of sol-gel parameters on sol to gel transitions.

FTIR spectra of unsupported uncalcined polymeric alumina membranes prepared by EAA derived sols are given in Fig. 5. EAA is known to have ketonic and enolic structure 


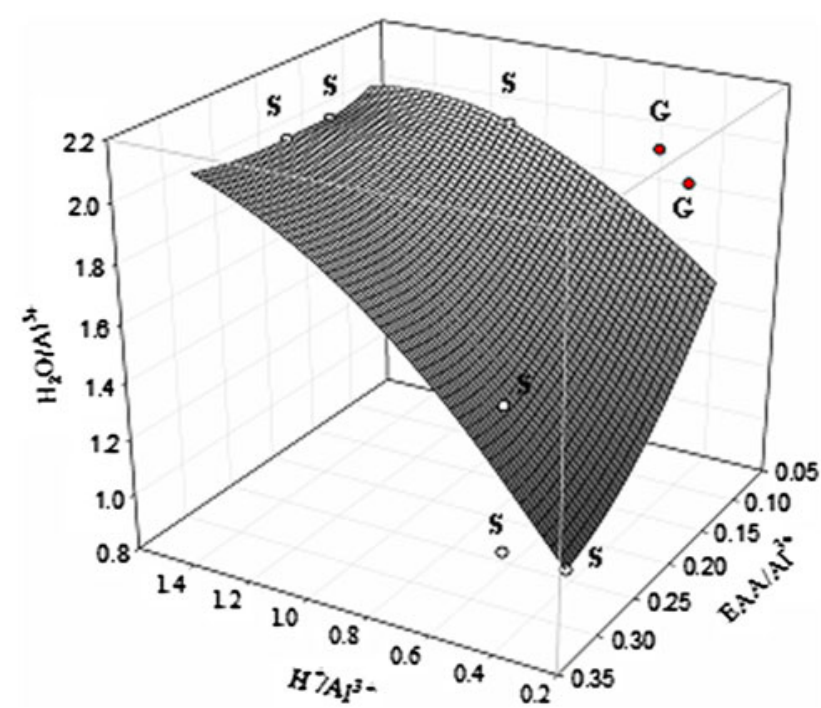

Fig. 4 The influence of sol-gel parameters on polymeric boehmite sol-gel transitions (S: sol; G: gel)

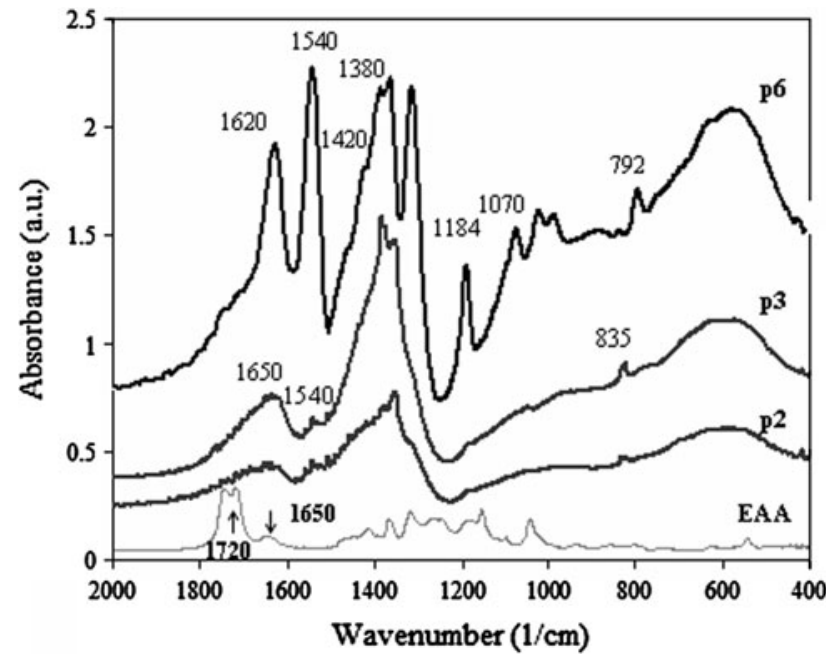

Fig. 5 FTIR spectra of polymeric unsupported uncalcined alumina membranes

forms. The enolic form of $\beta$-diketones contains a reactive hydroxy group which reacts readily with metal alkoxides [31]. The number of hydrolysable alkoxo groups decreases and additional coordination sites at the metal centers are blocked as a consequence of chelation. It was reported that the rate of hydrolysis and the extent of cross-linking in the formed network are decreased as a result of chelation [32]. Kessler et al. [33] stated that hydrolysis and polycondensation reactions of metal alkoxides facilitated by the chemical modification and their kinetics have no direct relation to the sol-gel transformation. In the IR spectrum of EAA, two characteristic bands located at 1,720 and $1,650 \mathrm{~cm}^{-1}$ were assigned to the $\mathrm{C}-\mathrm{O}$ stretching vibrations of the ketonic and enolic forms, respectively [34]. Although, band located at $1,540 \mathrm{~cm}^{-1}$ is too weak for $\mathrm{p} 2$ and $\mathrm{p} 3$, the strong bands for $\mathrm{p} 6$ at $1620(v \mathrm{C}-\mathrm{O})$ and 1540 $(\nu \mathrm{C}-\mathrm{C}) \mathrm{cm}^{-1}$ as well as 1,420 and $1,380 \mathrm{~cm}^{-1}\left(\delta \mathrm{CH}_{3}\right)$ indicated the formed chelate complex with aluminium secbutoxide [34-36]. A certain amount of EAA is thus necessary for the formation of a chelated complex. The formation of such chelated complexes in organic media modifies the hydrolysis/condensation reaction rates which may control the condensation behaviour of the hydrolyzed species forming the stable polymeric sol particles without precipitation. Bands located at 1,070 and $1,184 \mathrm{~cm}^{-1}$ were attributed to the symmetrical and unsymmetrical $\mathrm{Al}-\mathrm{OH}$ bending modes. However, absence of these bands for $\mathrm{p} 3$ sol might be due to the almost complete condensation of the hydrolysed species to form oxide networks because of high $\mathrm{H}_{2} \mathrm{O}$ and $\mathrm{H}^{+} / \mathrm{Al}^{3+}$ molar ratios with the lowest EAA content leading also to an increase in the particle size. The stretching $\mathrm{Al}-\mathrm{O}$ modes of octahedral species $\left(\mathrm{AlO}_{6}\right)$ are found below $900 \mathrm{~cm}^{-1}$ as well as the bending modes at $420 \mathrm{~cm}^{-1}$ that could indicate the formation of $\mathrm{Al}-\mathrm{O}-\mathrm{Al}$ network through condensation reactions.

The effect of process parameters on the formation of the polymeric boehmite sol was also investigated by ${ }^{27} \mathrm{Al}$ MAS-NMR and the spectra are given in Fig. $6 .{ }^{27} \mathrm{Al}$ NMR provides information on 4-, 5-, and 6-coordinated A1 species in solution and in the solid state. In ${ }^{27} \mathrm{Al}$ NMR data, characteristic chemical shifts for oxygen coordination by $\mathrm{Al}$ are the following; octahedral from -30 to $15 \mathrm{ppm}$, pentacoordinated $25-40 \mathrm{ppm}$ and tetrahedral $40-80 \mathrm{ppm}$ [37]. Oxygen atoms are arranged in octahedral coordination around $\mathrm{Al}$ and are organized in parallel layers linked by hydrogen bonds in boehmite. Boehmite to $\gamma-\mathrm{Al}_{2} \mathrm{O}_{3}$ conversion results in the formation of the tetrahedrally coordinated $\mathrm{Al}$ as well as octahedrally coordinated $\mathrm{Al}$ [38]. The spectrum is formed by one intense peak at $-7.5 \mathrm{ppm}$ as well as two components at 55 , and $-78 \mathrm{ppm}$ for sample p3. Zero ppm for ${ }^{27} \mathrm{Al}-\mathrm{NMR}$ resonance was assigned to octahedrally coordinated Al species in polycrystalline boehmite. This resonance shifted to $-7.5,-4,-6.2 \mathrm{ppm}$ for the samples p3, p6, and p8, respectively which most likely may be due to an interaction between the chelating agent and aluminium. ${ }^{27} \mathrm{Al}-\mathrm{NMR}$ resonance at $63.5 \mathrm{ppm}$ was attributed to the single tetrahedrally coordinated aluminium [38]. The ill-defined chemical shift at about $60 \mathrm{ppm}$ for uncalcined samples indicated the presence of tetrahedrally coordinated $\mathrm{Al}^{+3}$ in $\mathrm{Al}_{13} \mathrm{O}_{4}(\mathrm{OH})_{24}\left(\mathrm{H}_{2} \mathrm{O}_{\mathrm{x}}\right)^{+7}$ $\left(\mathrm{Al}_{13}\right.$ ion) cationic species [39]. This chemical shift is less prominent for $\mathrm{p} 6$ sol which has the lowest hydrolysis ratio indicating that the uncalcined structure is formed heavily by branched polymeric species.

Heat treatment upon $500{ }^{\circ} \mathrm{C}$ caused the increase in chemical shifts at $59,27 \mathrm{ppm}$ as well as at $-5.5 \mathrm{ppm}$ 
Fig. $6{ }^{27} \mathrm{Al}-\mathrm{MAS}$ NMR pattern of uncalcined polymeric unsupported alumina membrane a p3, b p6, c $500{ }^{\circ} \mathrm{C}$ heat treated p8
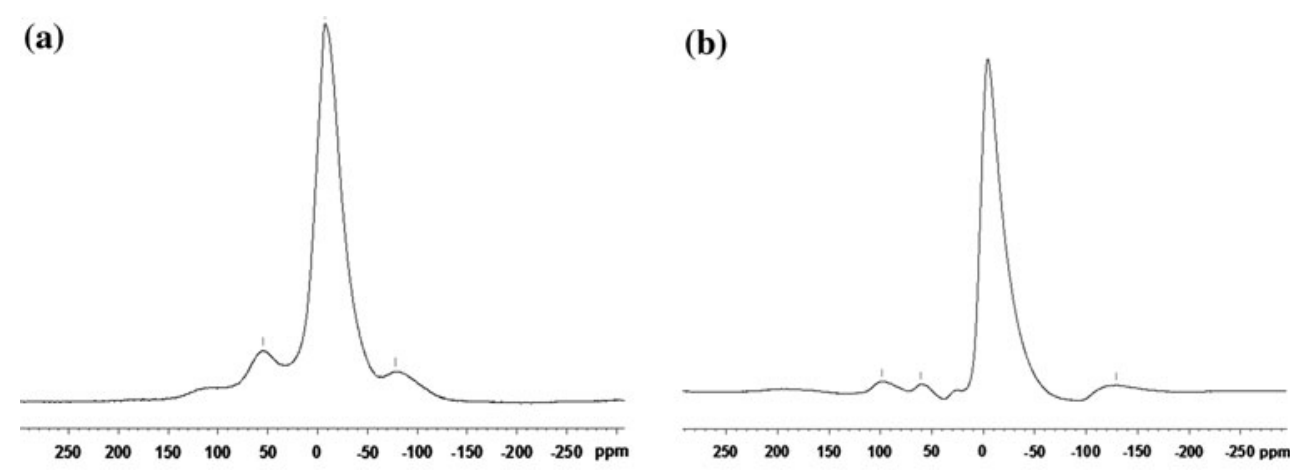

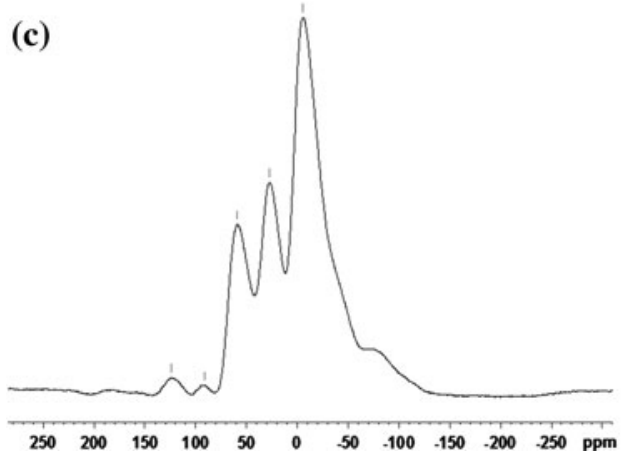

which was assigned to 4, 5 and 6-coordinated Al atom. Chemical shifts of tetra and octahedral components indicated the phase transformation to $\gamma-\mathrm{Al}_{2} \mathrm{O}_{3}$. The chemical shift at about $27 \mathrm{ppm}$ also indicated the presence of amorphous pentacoordinated phase [40].

The particle size distributions of sols aged in a refrigerator $\left(+4{ }^{\circ} \mathrm{C}\right)$ for 2 -months are given in Fig. 7. It was not possible to determine the particle size distributions of freshly prepared polymeric boehmite sols by dynamic light scattering. The average particle size varied in the $1-10 \mathrm{~nm}$ range depending on parameters that control the hydrolysis and condensation reactions. Smaller EAA content with high acid molar ratio $\left(\mathrm{H}^{+} / \mathrm{Al}^{3+}=1\right)$ (p3) caused the

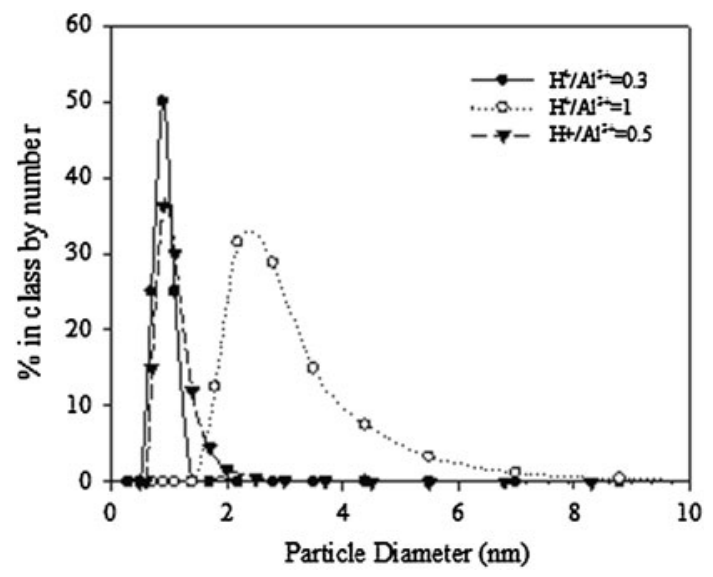

Fig. 7 Particle size distributions of aged polymeric boehmite sols formation of twofold larger particles compared to p6 and p8 sol particles. Increasing from 0.3 (p6) to 0.5 (p8) did not significantly affect particle size distributions as given in Fig. 7. It was previously shown in Fig. 2 that there was a threshold $\mathrm{H}^{+} / \mathrm{Al}^{3+}$ molar ratio on particle size for colloidal sols for which effect on particle size less important. It may be possible in this work that the $\mathrm{H}^{+} / \mathrm{Al}^{3+}$ molar ratio is above the threshold value for polymeric sols and a decrease in EAA content from 0.3 to 0.1 (p8 to p3) is mostly responsible for the twofold increase in sol particle size. Kreiter et al. [41] reported that acetylacetone stabilized titania and zirconia nanoparticle sols with particle sizes of 1 and $2 \mathrm{~nm}$ can be prepared successfully.

The physisorption isotherm of $500{ }^{\circ} \mathrm{C}$ treated unsupported polymeric alumina membrane changes from Type IV to Type I as the AA/Al ${ }^{3+}$ ratio changed from 0.4 (p02) to 0.3 (p03) as shown in Fig. 8. The Type IV isotherm with $\mathrm{H} 2$ hysteresis loop is characteristic of mesoporous alumina membranes synthesised from colloidal route as shown in Fig. 8a. A typical H2 hysteresis loop is commonly observed for mesoporous materials with interconnected pore networks of different sizes and shapes [42]. A considerable increase in the microporosity content indicated by Type I isotherm through the control of reaction conditions might allow to design of microporous alumina membranes with controlled pore structures. The solid state pore structure properties of the $500{ }^{\circ} \mathrm{C}$ heat treated membranes consolidated from polymeric and colloidal sols are summarized in Table 2. High $\mathrm{AA} / \mathrm{Al}^{3+}$ ratios resulted in a 
Fig. 8 Sorption isotherms of $500{ }^{\circ} \mathrm{C}$ heat treated alumina membrane a colloidal, b polymeric with corresponding sol $\mathrm{AA} / \mathrm{Al}^{3+}$ molar ratios of 0.4 and 0.3

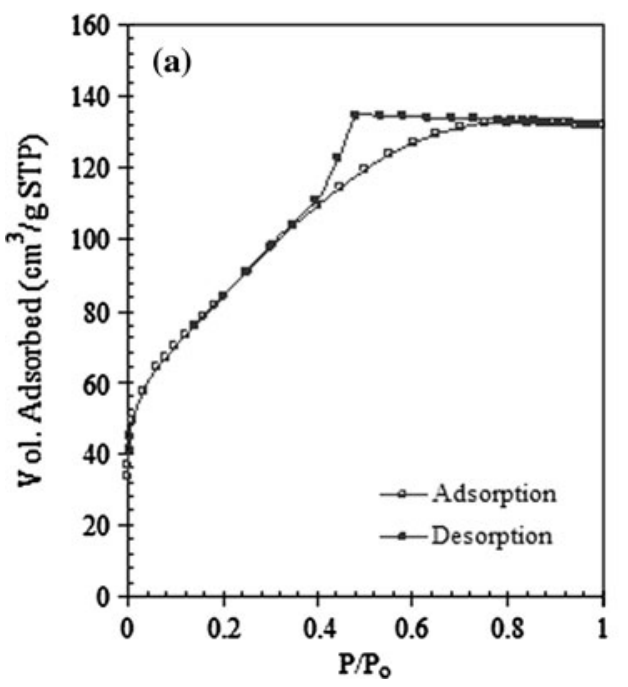

Table 2 Pore structure properties of $500{ }^{\circ} \mathrm{C}$ treated unsupported alumina membrane with respect to sol $\mathrm{AA} / \mathrm{Al}^{3+}$ molar ratio

\begin{tabular}{|c|c|c|c|c|c|c|}
\hline \multirow[t]{2}{*}[\mathrm{AA}]{$/\left[\mathrm{Al}^{3+}\right]$} & \multicolumn{2}{|c|}{$\begin{array}{l}\text { Surface area } \\
\left(\mathrm{m}^{2} / \mathrm{g}\right)\end{array}$} & \multirow[t]{2}{*}{ Porosity $^{\mathrm{a}} \%$} & \multicolumn{3}{|c|}{ Pore size $(\mathrm{nm})$} \\
\hline & BET & Langmuir & & H. K. & $\mathrm{BJH}_{\text {Des }}$ & $\mathrm{BJH}_{\mathrm{Ads}}$ \\
\hline $0.4(\mathrm{p} 02)$ & 132 & 180 & 23 & 0.87 & 2.65 & 2.73 \\
\hline $0.3(\mathrm{p} 03)$ & 382 & 544 & 37 & 0.83 & 2.06 & 2.01 \\
\hline Colloidal $^{\mathrm{b}}$ & 305 & 434 & 40 & & 2.80 & 2.70 \\
\hline
\end{tabular}

a Single point pore volume was used

b Sol particle size is $13 \mathrm{~nm}$

larger pore size and smaller surface area with a low porosity as shown in Table 2 . This may be due to the influence of the increasing chelating agent content on the gelation and consolidation behaviour of the sol particles during drying. Kessler et al. [33] reported that the use of chelating only ligand (e.g. acetylacetonate) results in dense film because of ligand mobility. Microporosity can be achieved through the application of ligands possessing both chelating and bridging properties in order to decrease the ligand mobility. They proposed that the whole sol formation process is directed not by kinetics of hydrolysis and polycondensation, but by the self assembly of ligands.

Decrease in pore size and increase in surface area of polymeric membrane (p03) in comparison with the colloidal counterparts, may result in significant improvements on membrane properties in terms of finer microstructure, layer homogeneity without cracks and defects.

\subsection{Thermal/phase evaluation and stability of alumina membranes}

XRD patterns of the $\mathrm{p} 3$ and $\mathrm{p} 6$ unsupported membranes heat treated in the $600-800{ }^{\circ} \mathrm{C}$ range are given in Fig. 9. Three $\gamma-\mathrm{Al}_{2} \mathrm{O}_{3}$ peaks (JCPDS, card file 10-0425) were identified in the $800{ }^{\circ} \mathrm{C}$ heat treated membrane pattern while heat treatment below $800{ }^{\circ} \mathrm{C}$ resulted in fully amorphous structures. This might be related to finer structures with very small particle sizes increasing the transformation temperature to the crystalline gamma phase. Amorphous structure of gamma phase has also been supported in NMR spectrum with pentacoordinated $\mathrm{Al}^{3+}$ ion for the $500{ }^{\circ} \mathrm{C}$ heat treated
Fig. 9 XRD patterns of a $\mathrm{p} 3$ and $\mathbf{b}$ p6 heat treated at different temperatures
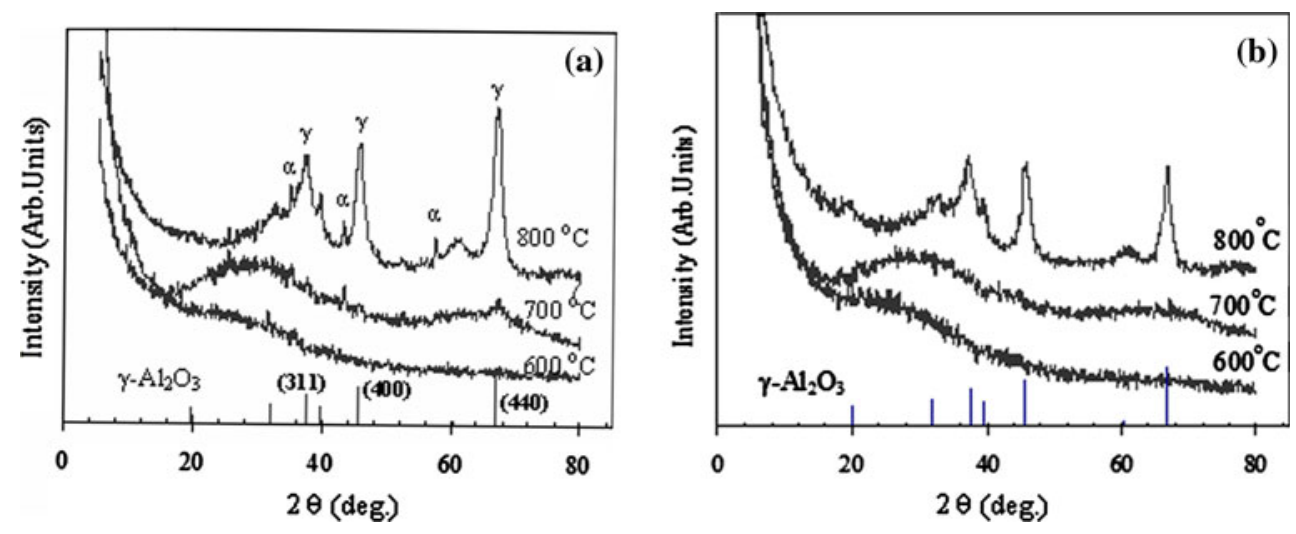


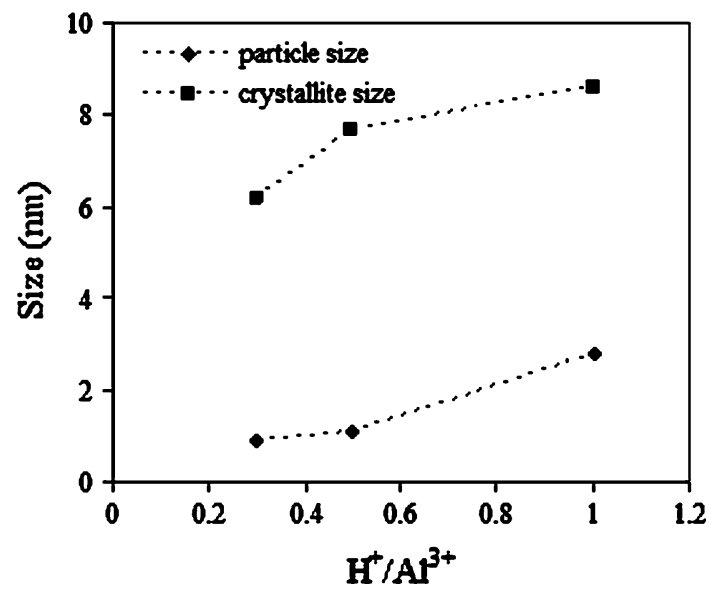

Fig. 10 Effect of process parameters on the particle size of the sols and the crystallite size of the $800{ }^{\circ} \mathrm{C}$ heat treated membranes

membranes. Although dominant phase was gamma for $800{ }^{\circ} \mathrm{C}$ heat treated p3 unsupported membranes, alpha phase crystals began to nucleate in contrast to $\mathrm{p} 6$ sample which might be related with differences in the sol particle sizes (alpha phase: JCPDS, card file 46-1212).

The crystallite sizes of the $800{ }^{\circ} \mathrm{C}$ heat treated unsupported membranes were determined by using Scherrer equation and the gamma (440) reflections. The variation of the particle size of the polymeric boehmite sols and the crystallite size of the $800{ }^{\circ} \mathrm{C}$ heat treated unsupported membranes with acid content of the sol is given in Fig. 10. The particle and crystallite size both increased with increasing sol acid content due to the fast hydrolysis/condensation reactions. Highly branched polymeric structures could be formed because of condensation of highly hydrolysed species as a consequence of the increase in sol acid content. The crystallite size of the heat treated membranes also increased in accordance with the sol particle size. The rate of nucleation and the successive growth of crystallites are higher in membrane films formed from smaller particles due to the presence of higher surface areas during the phase transformation upon heat treatment.

Boehmite transforms upon heating to a series of transitional aluminas $\left(\gamma-, \delta-, \theta-\mathrm{Al}_{2} \mathrm{O}_{3}\right)$ and finally to the thermodynamically stable $\alpha-\mathrm{Al}_{2} \mathrm{O}_{3}$ through dehydration and atomic rearrangements. A typical sequence of crystallization with approximate temperatures $\left({ }^{\circ} \mathrm{C}\right)$ is the following [38];

$\gamma-\mathrm{AlOOH} \stackrel{300}{\longrightarrow} \gamma-\mathrm{Al}_{2} \mathrm{O}_{3} \stackrel{850}{\longrightarrow} \delta-\mathrm{Al}_{2} \mathrm{O}_{3} \stackrel{1100}{\longrightarrow} \theta-\mathrm{Al}_{2} \mathrm{O}_{3} \stackrel{1200}{\longrightarrow} \alpha-\mathrm{Al}_{2} \mathrm{O}_{3}$

Figure 11 shows typical TGA/DTA curves of polymeric alumina unsupported membranes. The sharp weight loss in the temperature interval of $80-170{ }^{\circ} \mathrm{C}$ is due to the loss of water and solvent. The decomposition of organic groups and the elimination of adsorbed water in the membrane pores

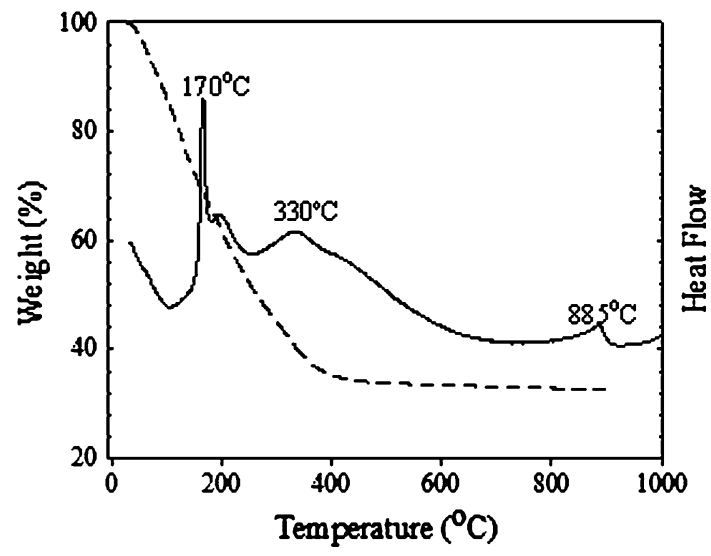

Fig. 11 DTA and TGA curves of unsupported alumina membranes (p2)

most likely occur in the $170-300{ }^{\circ} \mathrm{C}$ range. The slower gradual weight loss (wt $\sim 12 \%$ ) in the $300-450{ }^{\circ} \mathrm{C}$ range may correspond to the boehmite phase transformation to $\gamma$ $\mathrm{Al}_{2} \mathrm{O}_{3}$ by the elimination of $\mathrm{OH}^{-}$groups [43]. The weight loss beyond $600{ }^{\circ} \mathrm{C}$ was negligible. The exothermic peaks observed at 330 and $885^{\circ} \mathrm{C}$ may correspond to the phase transformation of boehmite to amorphous gamma alumina and the crystallization of the gamma phase, respectively. Crystallization of the gamma phase at $\sim 850^{\circ} \mathrm{C}$ appear to be correlated with XRD pattern in Fig. 9 in which pure gamma peaks were detected at temperatures above $800{ }^{\circ} \mathrm{C}$. There is also no evidence of the formation of crystalline gamma phase below $800{ }^{\circ} \mathrm{C}$. This temperature is considerably higher than that of the crystallization of gamma phase from colloidal boehmite particles [38]. Spijksma et al. [44] also reported crystallization at around $750{ }^{\circ} \mathrm{C}$ in the microporous titania-zirconia composite membranes derived from diethanolamine modified precursors which was considerably higher than $\sim 400{ }^{\circ} \mathrm{C}$ for pure titania and zirconia.

The shrinkage and temperature derivative of shrinkage curves for p3 is given in Fig. 12 indicating four major shrinkage events located at $160,290,837$ and $1,100{ }^{\circ} \mathrm{C}$.

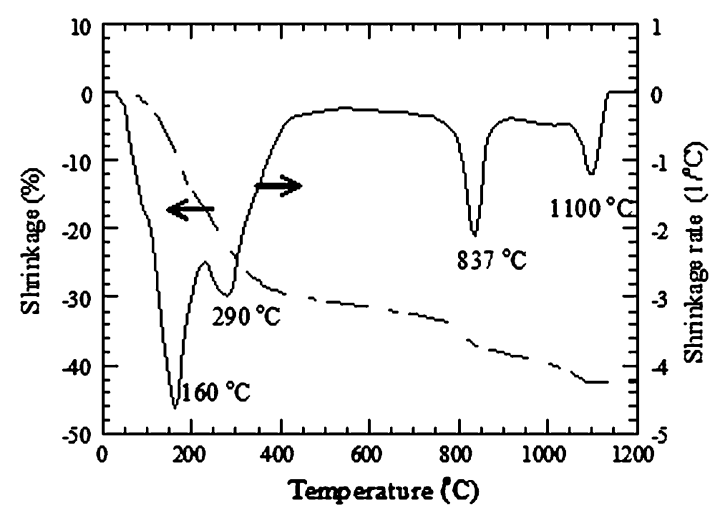

Fig. 12 Shrinkage and shrinkage rate curves of p3 
These temperatures agree well with the DTA exotherms suggesting solvent removal, boehmite to gamma alumina transformation and the gamma alumina crystallization at $\sim 850{ }^{\circ} \mathrm{C}$. The strong peak observed at $1,100{ }^{\circ} \mathrm{C}$ most likely is related with the final phase transformation to alpha alumina. The total thermal shrinkage was about $42 \%$ up to $1,200{ }^{\circ} \mathrm{C}$.

\subsection{Gas permeation through colloidal alumina membranes}

The permeance values for the 3-layer colloidal alumina membranes were independent of pressure. This implies that the dominant gas transport mechanism is Knudsen diffusion which also was supported by the presence of $2.5-3 \mathrm{~nm}$ pore sizes in these membranes [15]. Improved permeability with relatively high permselectivity has been obtained for the 3layer graded alumina membranes as compared to ungraded membrane as shown in Fig. 13. The use of graded structures for the intermediate layers by applying size-controlled boehmite sols to improve the permeation properties has been reported by Gu and Oyama [6].

Permeance values show an inverse square root dependence on temperature and molecular weight of the gas molecules according to Knudsen diffusion mechanism and the permeability $\left(\mathrm{mol} / \mathrm{m}^{2} \mathrm{sPa}\right)$ is given by $[23,45]$;

$$
\left(\frac{P}{l}\right)_{\text {Knudsen }}=\frac{\varepsilon d_{\mathrm{p}}}{\tau l}\left(\frac{8}{9 \pi M R T}\right)^{1 / 2}
$$

where $\varepsilon$ is the porosity, $d_{p}$ is the pore diameter $\tau$ is the tortuosity, $l$ is the membrane thickness, $M$ is the molecular mass of the permeating species, $T$ is the absolute temperature, and $R$ is the gas constant. The normalized permeance values $(P / l)(M T)^{0.5}=\left(\varepsilon d_{\mathrm{p}} / \tau l\right)(8 / 9 \pi R)^{0.5}$ are plotted for graded and ungraded structures in Fig. 14. Almost similar values for all three gases independent of temperature indicating that the gas transport through the membrane was involved only Knudsen diffusion. The values of normalized permeance gets even closer for the graded structured

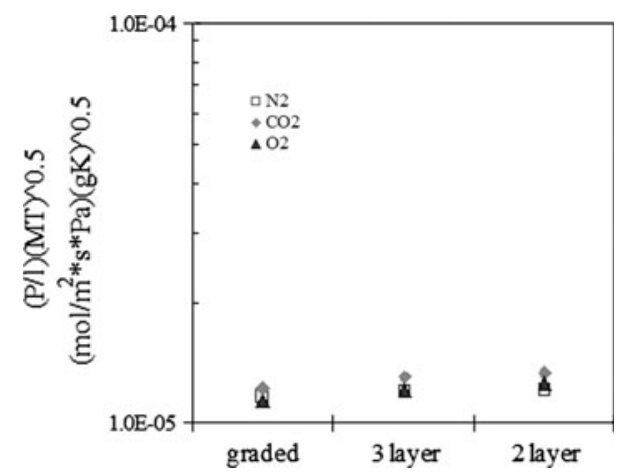

Fig. 14 Normalized permeance values for alumina membranes

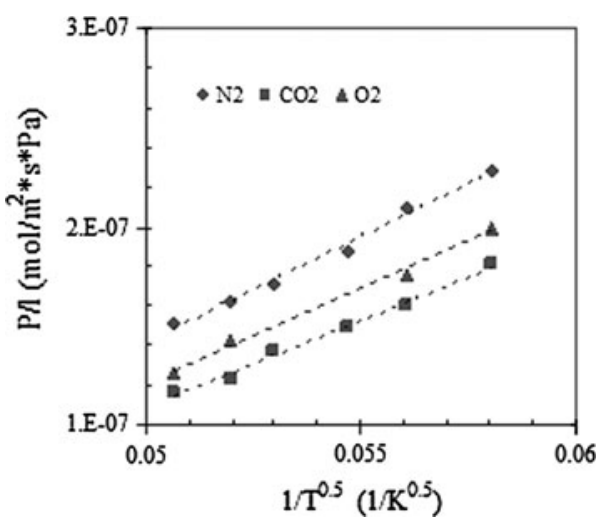

Fig. 15 Permeance versus $1 / \mathrm{T}^{0.5}$ for the graded alumina membrane

alumina membranes indicating a more homogeneous and defect-free membrane layer as shown in the same figure.

The permeance values of the gases are plotted against the inverse square root of temperature for graded alumina membranes along with the corresponding linear regression fits in Fig. 15. This relatively good regression fit $\left(R^{2}=\right.$ $0.991-0.989)$ confirms again that Knudsen diffusion was the dominant transport mechanism where molecule-pore wall interactions are more significant than molecule-molecule interactions.
Fig. 13 Permeances through three layer alumina membranes with a un-graded, b graded structures
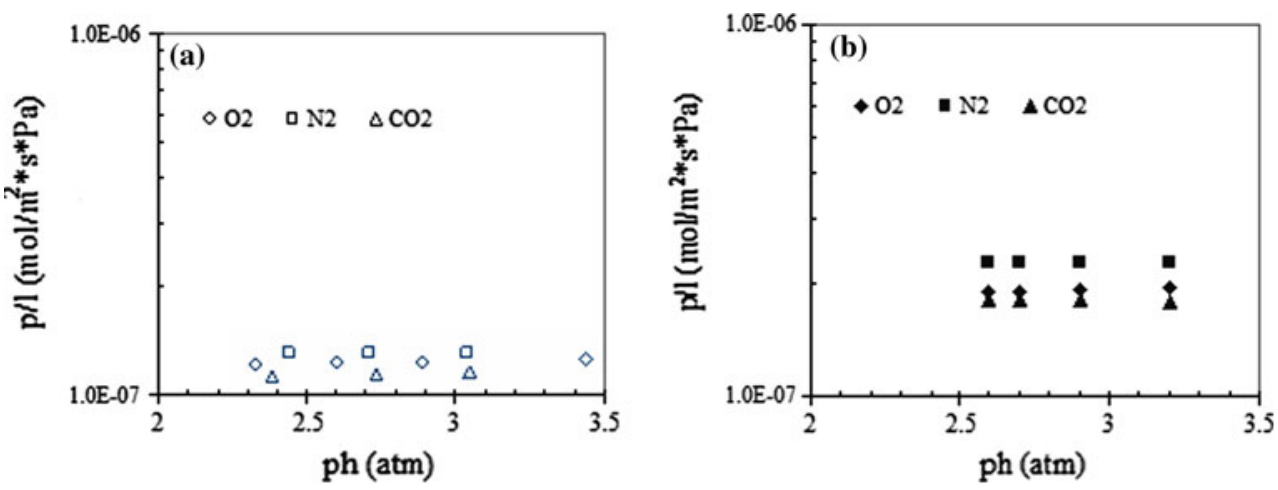
Fig. 16 a Permeances through 2-layer polymeric alumina membranes (p3) as function of pressure, and $\mathbf{b}$ temperature

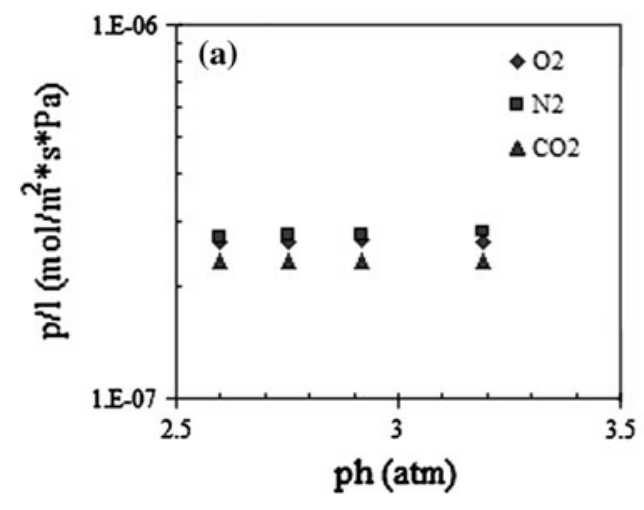

3.5 Gas permeation through polymeric alumina membranes

The permeances through 2-layer polymeric alumina membrane (p3) as a function of pressure and temperature of different gases are shown in Fig. 16. Characteristic Knudsen diffusion behaviour can be observed in these figures as those had inverse temperature dependence and constant values with pressure.

Knudsen plot of p3 membrane is given in Fig. 17c, where the dashed line was obtained by fitting the data for the simplified Knudsen diffusion permeability equation [46];

$$
\left(\frac{P}{l}\right)_{\text {Knudsen }}=K \sqrt{\frac{1}{M R T}}
$$

where the value of constant $K$ depends on microstructural properties of membranes (pore size, porosity, tortuosity). The values of experimental and Knudsen diffusion equation derived permeances get even closer implying that the dominant transport through the membrane was Knudsen diffusion. The thickness of membrane was determined as about $300 \mathrm{~nm}$ from the SEM micrograph of pulled out region on edge top surface as shown in Fig. 17a. Finer membrane structures with relatively thin layer compared to the colloidal mesoporous alumina membranes have been
Fig. 17 a SEM micrographs of top surfaces $\mathrm{p} 3$-membrane (50 KX), b100 KX, c Knudsen plot of p3 membrane, d permeances as a function of kinetic diameters
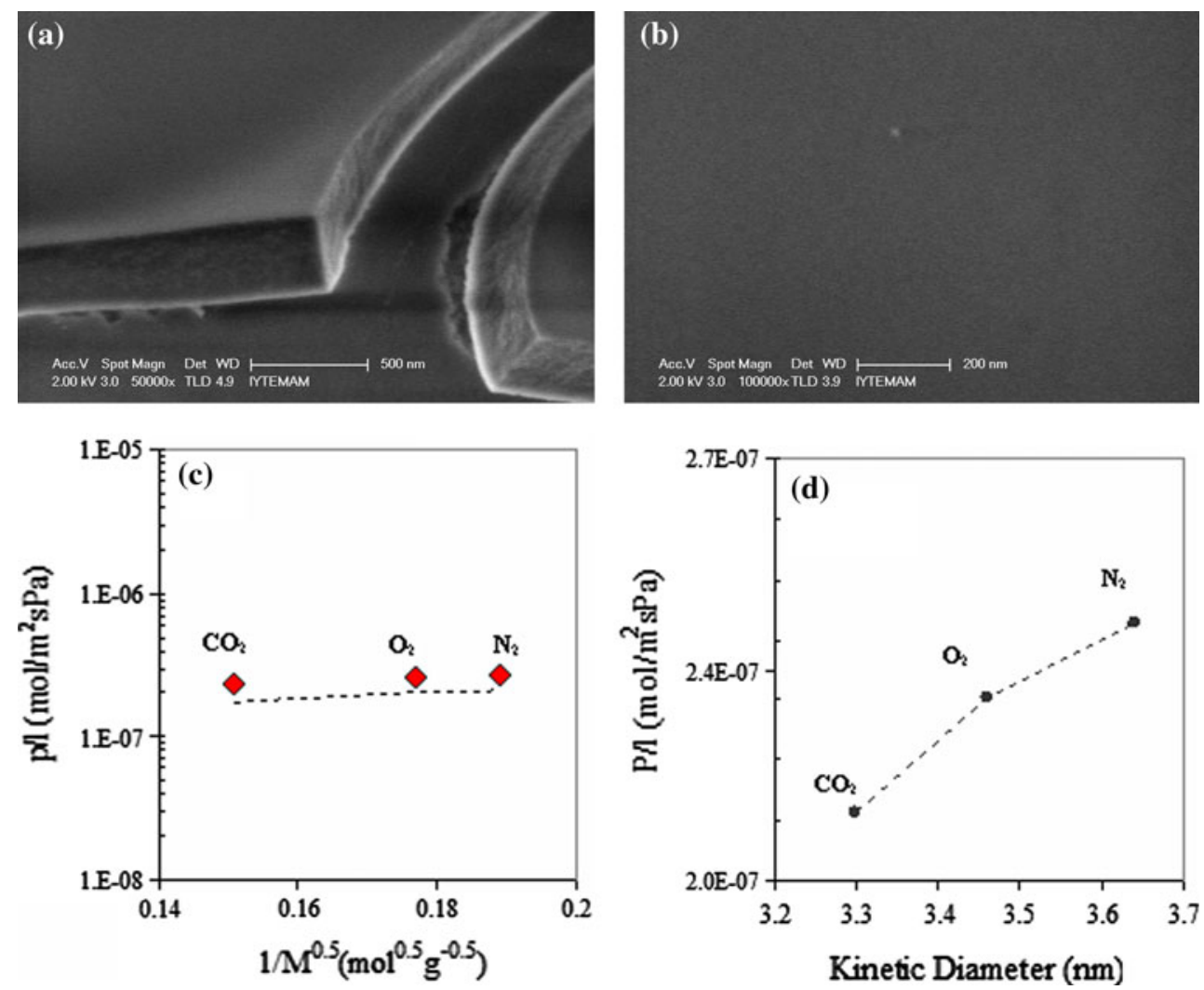
obtained through the packing of polymeric boehmite species but, permeation behaviour showed the Knudsen diffusion behaviour and molecular sieving effect could not been achieved as shown in Fig. 17d.

The previously reported permselectivities [15, 47-49] indicate Knudsen diffusion dominated transport with either small positive or negative deviation from the theoretical Knudsen separation value of $\mathrm{CO}_{2}$ to $\mathrm{N}_{2}$ permeances (0.8). The $\mathrm{CO}_{2} / \mathrm{N}_{2}$ permselectivities determined in this work for polymeric alumina membranes is comparable with those reported in the literature. The presence and the nature of microcracks/defects are more determining and should be controlled in these microporous materials towards their successful application in gas separations. The close control of microstructural development during heat treatment with a better understanding of the consolidation conditions like dipping time, withdrawal rate and sol concentration would make the design of defect free microporous membranes with molecular sieving capabilities possible.

\section{Conclusions}

Polymeric aged boehmite sols with species down to $\sim 2 \mathrm{~nm}$ in diameter could be prepared depending on the controlled sol-gel process conditions. Modification of the $\mathrm{Al}$-alkoxides and control of hydrolysis/condensation rates by chelating agents made the successful preparation of stable polymeric boehmite sols possible and the uncontrolled precipitation and/or gelation was prevented during sol formation. The coordination of $\mathrm{Al}^{3+}$ atom in the polymeric structure was determined from ${ }^{27} \mathrm{Al}$ MAS-NMR spectra. The observed dominant chemical shifts at $-7.5,-4,-6.2 \mathrm{ppm}$ for the samples indicated the presence of octahedrally coordinated boehmite. The transformation of boehmite to amorphous gamma alumina phase has been elucidated by increasing peak intensity at $56 \mathrm{ppm}$ corresponding to tetrahedrally coordinated $\mathrm{Al}^{3+}$ atom for the $500{ }^{\circ} \mathrm{C}$ heat treated membranes. The heat treated acetyl-acetone derived alumina membranes had a microporosity of about $34 \%$ with $\mathrm{H}-\mathrm{K}$ pore sizes of about $0.83 \mathrm{~nm}$. The phase evolution of the polymeric alumina unsupported membranes showed that the transformation from boehmite to crystalline gamma phase commences at $800{ }^{\circ} \mathrm{C}$ with well defined (400) and (440) reflections. Almost constant crystallite sizes of $8 \mathrm{~nm}$ in all heat treated unsupported membranes at this temperature was determined with small variations in sol particle sizes from DLS measurements. The amorphous nature of this structure up to relatively high temperatures may cause higher thermal stability by reducing the extent of thermally activated microcrack formation on membrane surface.

Pressure independent behaviour of permeance values for two and three layer colloidal alumina membranes implied that the dominant transport mechanism is Knudsen diffusion. Almost complete agreement was observed between experimental and Knudsen diffusion equation derived permeances for the polymeric alumina membranes with thicknesses of about $300 \mathrm{~nm}$.

The preparation of thin defect-free microporous alumina membrane layers necessitates the optimization of process parameters controlling the sol species structures closely. Further research on the influence of such parameters on size and structure of polymeric species in boehmite polymeric sols may significantly develop our understanding of the gas permeation behaviour and structural evolution of these promising materials for separation and other applications.

Acknowledgments The authors gratefully acknowledge the Middle East Technical University (METU) Central Laboratory for performing ${ }^{27} \mathrm{Al}$ MAS-NMR characterization experiments. The authors thank the Centre for Materials Research at the İzmir Institute of Technology for $\mathrm{XRD} / \mathrm{SEM}$ analysis.

\section{References}

1. Tsuru T (2008) J Sol Gel Sci Technol 46:349-361

2. Brinker CJ, Ward TL, Sehgal R, Raman NK, Hietala SL, Smith DM, Hua D, Headley TJ (1993) J Membr Sci 77:165-179

3. Boffa V, Castricum HL, Garcia R, Schmuhl R, Petukhov V, Blank DHA, ten Elshof JE (2009) Chem Mater 21:1822-1828

4. Yoldas BE (1975) Ceram Bull 54(3):289-290

5. Anderson MA, Gieselmann MJ, Xu Q (1988) J Membr Sci 39:243-258

6. Gu Y, Oyama ST (2007) J Membr Sci 306:216-327

7. Shqau K, Mottern ML, Yu D, Verweij H (2006) J Am Ceram Soc 89(6):1790-1794

8. Mallada R, Menendez M (2008) Inorganic membranes: synthesis, characterization and applications. Elsevier Science, Netherlands

9. Yoshino Y, Suzuki T, Nair BN, Taguchi H, Itoh N (2005) J Membr Sci 267:8-17

10. Gopalakrishnan S, Yoshino Y, Nomura M, Nair BN, Nakao J (2007) J Membr Sci 297:5-9

11. Lin YS, Chang C-H, Gopalan R (1994) Ind Eng Chem Res 33:860-870

12. Kuzniatsova T, Mottern ML, Shqau K, Yu D, Verweij H (2008) J Membr Sci 316(1-2):80-88

13. Uhlhorn RJR, Huis In't Veld MHBJ, Keizer K, Burggraaf AJ (1992) J Mater Sci 27:527-537

14. Leenaars AFM, Keizer K, Burggraaf AJ (1984) J Mater Sci 19:1077-1088

15. Uhlhorn RJR, Keizer K, Burggraaf AJ (1989) J Membr Sci 46:225-241

16. Okubo T, Watanabe M, Kusakabe K, Morooko S (1990) J Mater Sci 25:4822-4827

17. Yu C-Y, Sea B-K, Lee D-W, Park S-J, Lee K-Y, Lee K-H (2008) J Colloid Interface Sci 319(2):470-476

18. Nijmeijer A, Kruidhof H, Bredesen R, Verweij H (2001) J Am Ceram Soc 84(1):136-140

19. Lin Y-S, Burggraaf AJ (1991) J Am Ceram Soc 74(1):219-224

20. Zahir MH, Sato K, Mori H, Iwamoto Y (2006) J Am Ceram Soc 89(9):2874-2880

21. Lafarga D, Lafuente A, Menendez M, Santamaria J (1998) J Membr Sci 147:173-185 
22. Keizer K, Uhlhorn RJR, Van Vuren RJ, Burggraaf AJ (1988) J Membr Sci 39:285-300

23. Lee D, Zhang L, Oyama ST, Niu S, Saraf RF (2004) J Membr Sci 231:117-126

24. Chen H-I, Shiau J-D, Chu C-Y, Huang T-C (2003) Sep Purif Tech 32:247-254

25. Gu Y, Oyama ST (2007) Adv Mater 19:1636-1640

26. Gu Y, Hacarlioglu P, Oyama ST (2008) J Membr Sci 310:28-37

27. Topuz B, Ciftçioğlu M, Özkan F (2004) Key Eng Mater 264-268:399-402

28. Topuz B (2009) PhD Thesis, Izmir Institute of Technology, İzmir, Turkey

29. Burggraaf AJ, Cot L (1996) Fundamentals of inorganic membrane science and technology. Elsevier, Amsterdam

30. Gu Y, Meng G (1999) J Eur Ceram Soc 19:1961-1966

31. Sanchez C, Livage J, Henry M, Babonneau F (1988) J Non Cryst Solids 100:65-76

32. Lichtenberger R, Puchberger M, Baumann SO, Schubert U (2009) J Sol Gel Sci Technol 50:130-140

33. Kessler VG, Spijksma GI, Seisenbaeva GA, Hakansson S, Blank DHA, Bouwmeester HJM (2006) J Sol Gel Sci Technol 40:163-179

34. Jing C, Zhao X, Zhang Y (2007) Mater Res Bull 42(4):600-608

35. Fu Q, Cao C-B, Zhu H-S (1999) Thin Solid Films 348:99-102

36. Babonneau F, Coury L, Livage J (1990) J Non Cryst Solids 121:153-157
37. Hernandez C, Pierre AC (2001) J Sol Gel Sci Technol 20:227-243

38. Brinker CJ, Scherer GW (1990) Sol-gel science: the physics and chemistry of sol-gel processing. Academic Press, Boston

39. Nazar LF, Klein LC (1988) J Am Ceram Soc 71(2):C85-C87

40. Gonzalez-Pena V, Marquez-Alvarez C, Diaz I, Grande M, Blasco T, Perez-Pariente J (2005) Microporous Mesoporous Mater 80:173-182

41. Kreiter R, Rietkerk MDA, Bonekamp BC, van Veen HM, Kessler VG, Vente JF (2008) J Sol Gel Sci Technol 48:203-211

42. Rouquerol F, Rouquerol J, Sing K (1999) Adsorption by powders and porous solids: principles, methodology and application. Academic Press, London

43. Alphonse P, Courty M (2005) J Colloid Interface Sci 290: 208-219

44. Spijksma GI, Huiskes C, Benes NE, Kruidhof H, Blank DHA, Kessler VG, Bouwmeester HJM (2006) Adv Mater 18:2165-2168

45. de Lange RSA, Keizer K, Burggraaf AJ (1995) J Membr Sci 104:81-100

46. Boffa V, ten Elshof JE, Garcia R, Blank DHA (2009) Microporous Mesoporous Mater 118(1-3):202-209

47. Cho Y-K, Han K, Lee K-L (1995) J Membr Sci 104:219-230

48. Lee H-J, Yamauchi H, Suda H, Haraya K (2006) Sep Purif Tech 49(1):49-55

49. Kang BS, Hyun SH (1999) J Mater Sci 34:1391-1398 